\title{
MONISMO SOCIAL OU MORAL? DOS PRESSUPOSTOS TEÓRICO- SOCIAIS DA TEORIA DO RECONHECIMENTO DE AXEL HONNETH ${ }^{1}$
}

\author{
SOCIAL OR MORAL MONISM? ON THE SOCIAL-THEORETICAL \\ PRESSUPOSITIONS OF AXEL HONNETH'S THEORY OF RECOGNITION
}

\author{
NATHALIE BRESSIANI ${ }^{2}$ \\ (UFABC, Brasil)
}

\begin{abstract}
RESUMO
Este artigo visa compreender o estatuto do monismo do reconhecimento proposto por Axel Honneth, por meio de uma análise da relação que o autor estabelece entre reconstrução normativa e teoria social. Procuraremos inicialmente mostrar que, para reabrir o domínio do social e identificar um interesse mais realista à emancipação na sociedade, Honneth enfatiza, em seus primeiros textos, a importância dos padrões institucionalizados do reconhecimento e das lutas morais no interior de todos os processos de reprodução social. Retomando, em seguida, algumas das críticas dirigidas a ele dessa perspectiva, argumentaremos que, nos momentos em que afirma que o funcionamento da economia pode ser compreendido a partir da teoria do reconhecimento, Honneth ignora a especificidade dos mecanismos econômicos de reprodução. Estendendo esse argumento às várias dimensões da reprodução social, mobilizaremos então diferentes autores para mostrar que, nas passagens em que defende que o desenvolvimento da sociedade está ancorado nos três padrões normativos de reconhecimento, Honneth parece fundir o nível da reconstrução normativa com o da descrição social e atribuir, portanto, um estatuto teórico-social ao monismo do reconhecimento. Explicitando, então, uma alteração na argumentação do autor, que sublinha, em sua segunda contribuição à Redistribuição ou Reconhecimento?, que o monismo possui um estatuto moral e não teórico-social, dedicaremos as últimas seções do texto a uma analise da estratégia negativa de reconstrução mobilizada por ele, isto é, a estratégia de partir de uma fenomenologia da experiência de desrespeito para explicitar as expectativas normativas de reconhecimento sustentadas pelos sujeitos. Apontando, por fim, para o abandono dessa estratégia a partir de Sofrimento de Indeterminação, sugerimos que a atual solução adotada por Honneth está em elaborar um novo conceito de reconstrução normativa, por meio do qual ele procura reconstruir as estruturas normativas das instituições das sociedades modernas sem defender, com isso, que estas correspondem àquelas.
\end{abstract}

Palavras chaves: Axel Honneth. Reconhecimento. Reconstrução normativa. Teoria social. Experiência de desrespeito.

\begin{abstract}
This paper aims to understand the character of Axel Honneth's recognition monism, by analyzing the relationship he establishes between normative reconstruction and social description. At first, we will show that, to reopen the domain of the social and to identify a more realistic emancipation interest in society, Honneth tends to over emphasize, in early works, the importance of institutionalized recognition patterns and of moral struggles to all social reproduction processes. Resuming, in a second step, some criticisms directed to him because of that, we argue that, every time he states that the economy can be understood as a recognition order, Honneth overlooks the specificity of economic mechanisms of reproduction. Extending this argument to the various dimensions of social reproduction, we mobilize different authors to claim that, when he argues that the development of society is directly anchored on normative recognition patterns, Honneth seems to merge the level of normative reconstruction with that of social description and to attribute a social-theoretical status to his recognition monism. Drawing attention, in the last sections, to a change in Honneth's argumentative strategy,
\end{abstract}


once he claims, in his second contribution to Redistribution or Recognition?, that his monism has a moral not a social-theoretical character, we analyze his negative reconstruction strategy, that is, the strategy to draw on a phenomenology of the experiences of disrespect to reconstruct the normative recognition expectations held by the subjects. Pinpointing, at last, to the abandonment of this solution since Suffering from Indeterminacy, we suggest that Honneth's current solution consists in the development of a new conception of normative reconstruction, thought which he aims to reconstruct the normative structure of modern societies' institutions without claiming that these correspond to them.

Keywords: Axel Honneth. Recognition. Normative reconstruction. Social theory.Experience of disrespect.

Desde seus primeiros textos, Axel Honneth se opôs ao diagnóstico, defendido por grande parte dos teóricos críticos até então, de que o desenvolvimento da sociedade resulta parcial ou integralmente - da pressão por adaptação exercida sobre os indivíduos por sistemas sociais que teriam se tornado autônomos. Responsável pela radicalização da virada comunicativa empreendida por Jürgen Habermas, Honneth sustenta que elaborar uma teoria social da perspectiva de uma teoria dos sistemas implica perder de vista a dinâmica normativa que está na base da reprodução social como um todo. Para ele, as sociedades modernas não se caracterizam pelo surgimento de formas sistêmicas de integração, capazes de coordenar a ação pelas costas dos indivíduos, mas sim pela diferenciação de princípios de integração social, que se distinguem conforme se realizam por meio de "ligações emotivas, da adjudicação de direitos ou da orientação comum por valores” (Honneth 2003a, 159). É, nesse sentido, que ele reconstrói o processo de modernização social como um processo de desenvolvimento moral, no decorrer do qual três princípios de reconhecimento teriam se diferenciado: o do amor, o do respeito e o da estima social. ${ }^{3}$

Contrapondo-se então a Habermas, para quem o processo de modernização teria gerado uma diferenciação entre sistema e mundo da vida (Habermas 1995, 229-293), Honneth defende que a modernidade se caracteriza pela distinção e pela contínua institucionalização de três padrões normativos de reconhecimento que orientam, cada qual de uma forma, as relações sociais no interior das esferas da família, do direito e do trabalho. A normatividade da família é reconstruída com base na dinâmica de suas relações afetivas, no interior das quais as pessoas se reconheceriam mutuamente em suas carências naturais. A normatividade da esfera do direito, por sua vez, é resgata através da reconstrução do princípio do respeito, de acordo com o qual todos são universalmente reconhecidos como portadores dos mesmos direitos e deveres. Por fim, a normatividade do mercado é reconstruída a partir de sua lógica cooperativa, já que, por meio de sua atividade produtiva, os diferentes indivíduos contribuem reciprocamente para a satisfação das necessidades dos demais. Vinculada a essa esfera, a estima social desfrutada por cada um dependeria de sua contribuição individual a esse 
processo cooperativo. ${ }^{4}$

Embora não procure traçar uma separação rígida entre esses domínios, Honneth reconstrói a dinâmica interna de desenvolvimento de cada um deles remetendo-se à efetivação de um desses padrões normativos de reconhecimento. Ele defende, com isso, que os princípios do amor, do respeito e da estima se encontram socialmente institucionalizados e orientam, não apenas as expectativas e o comportamento dos sujeitos nos diferentes contextos de interação, como também os processos sociais de reprodução (Honneth 2003b). Assumindo o ponto de vista da teoria da ação, ele procura então "esclarecer os processos de mudança social remetendo-os às pretensões normativas estruturalmente inscritas na relação de reconhecimento recíproco" (Honneth 2003a, 157).

É, com base nisso, que Honneth defende que, longe de corresponder a um sistema funcional de coordenação da ação, que se encontra blindado da crítica e independe de qualquer normatividade, a economia capitalista se apoia, assim como o restante da sociedade, em princípios institucionalizados de reconhecimento e depende de um certo consenso moral a respeito de sua aplicação correta. De acordo com ele, o capitalismo não surgiu, nem se desenvolveu à margem das instituições sociais e dos processos de reprodução simbólica da sociedade e não pode ser compreendido como um sistema normativamente neutro, cujo desenvolvimento dependeria apenas de uma lógica sistêmica, destituída de quaisquer relações com os princípios normativos do reconhecimento (Honneth 1989). Se não fosse assim, afirma, não seria possível garantir o grau de cooperação necessário ao funcionamento do capitalismo (Honneth 2003c, 288). Argumento que valeria também para as demais esferas das sociedades modernas, cuja manutenção e desenvolvimento dependeriam da existência de um acordo acerca de sua legitimidade.

Esta tese é central para aos propósitos de Honneth, pois permite que ele defenda, na contra mão de Habermas, que todos os domínios e instituições sociais, dentre as quais a economia capitalista, se encontram ao alcance da crítica e podem ser alterados por meio de lutas sociais por reconhecimento. Afinal, longe de constituir algo fixo e imutável, a crença em sua legitimidade - medida com base nos padrões normativos de reconhecimento - está sempre sujeita a questionamentos e pode desaparecer a qualquer momento.

Grande parte dos interlocutores e comentadores de Honneth reconhece as vantagens decorrentes de sua guinada em direção à teoria da ação. Para eles, ao compreender a dinâmica normativa da reprodução social como um todo, Honneth é bem sucedido não só em seu objetivo de aproximar a teoria crítica da experiência dos sujeitos sociais, como também no de recolocar o capitalismo ao alcance da crítica. Apesar disso, sua estratégia de enfatizar a força 
modeladora do reconhecimento no interior dos processos de reprodução social é questionada, principalmente no que diz respeito às suas consequências para a teoria social e para o diagnóstico de patologias. Isso porque, com ela, Honneth parece reduzir a dinâmica dos processos de reprodução social às dinâmicas normativas das relações de reconhecimento. Como afirma Jean-Philippe Deranty:

o "monismo moral" que Honneth defende como sua posição específica leva a um
resultado ambíguo. Por um lado, ele parece constituir uma posição poderosa para
propósitos críticos. Pode-se dizer que todos os fenômenos sociais possuem uma
dimensão moral, que eles podem gerar sentimentos de injustiça e experiências de
sofrimento, de tal forma que nenhuma área da vida social deva ser excluída, em
princípio, da crítica e de tentativas práticas de transformação. O problema é que esse
resultado benéfico pode ser muito facilmente comprado ao preço de uma posição
reducionista na teoria social. Parece haver um deslize não percebido entre as
exigências críticas da teoria crítica (que deve ser, ao mesmo tempo, normativa e
monista) e as exigências conceituais da teoria social, de que as profundezas
institucionais da realidade social sejam adequadamente compreendidas (Deranty
2009,350 ).

A dimensão desse problema depende, contudo, de como os pressupostos teóricosociais aparentemente assumidos por Honneth são interpretados, isto é, depende de como compreendemos o papel atribuído por ele à gramática moral do reconhecimento no interior dos processos reais de desenvolvimento social.

\section{Monismo teórico-social?}

O objetivo de reabilitar uma crítica interna da economia capitalista é central ao projeto de Honneth. É, tendo-o em vista, que ele retoma Marx em seus primeiros textos e procura desenvolver um conceito crítico de trabalho social, por meio do qual poderia diferenciar formas alienadas e não alienadas de trabalho (Honneth 1980). Aos poucos, contudo, sua crítica à neutralização normativa da atividade do trabalho foi dando lugar à percepção de que ela não contém em si um potencial emancipatório. No momento em que se dá conta disso, Honneth deixa de mobilizar a relação entre o trabalhador e o produto de seu trabalho como padrão normativo e começa a desenvolver uma teoria crítica do reconhecimento.

A recusa de que a crítica social pode ser ancorada em uma noção de trabalho alienado não o leva, porém, a abandonar o projeto de desenvolver uma crítica interna da economia capitalista (Honneth 2000, 104-107). Chamando atenção à força modeladora das relações de reconhecimento mesmo no interior da economia, Honneth passa agora a criticá-la tendo em vista o contexto social que lhe serve de sustentação. Como afirma ele, "o critério de avaliação 
moral não pode estar relacionado com o caráter interno do próprio processo de trabalho, mas somente com o quadro institucional no qual ele está necessariamente ancorado" (Honneth 1995, xviii).

Crítico da posição antinormativista adotada por Habermas para descrever determinados âmbitos sociais, Honneth tenta explicitar as bases normativas da sociedade como um todo e defende que mesmo a economia, normalmente compreendida como uma esfera em que a ação é coordenada por imperativos sistêmicos, está ancorada na estrutura normativa do reconhecimento e depende de como os princípios do respeito igual e do mérito individual são interpretados em cada sociedade (Smith 2011, 337-8, Honneth 2003b, 164168). Nesse sentido, ele afirma não só que "as regras que organizam a distribuição de bens materiais derivam do grau de estima desfrutado pelos grupos sociais, de acordo com as hierarquias institucionalizadas de valores ou com uma ordem normativa" (Honneth 2001b, 43), mas também que a emergência do Estado de bem estar social corresponde a uma mudança na ordem de reconhecimento do capitalismo, que "pode ser entendida como a penetração do princípio do tratamento legal igual na esfera, previamente autônoma, da estima social" (Honneth 2003b, 176)

Defendendo, então, que a distribuição material e a divisão social do trabalho dependem diretamente de como os princípios do respeito e da estima são interpretados em determinada sociedade, Honneth afirma que elas podem ser avaliadas, criticadas e transformadas com base em novas interpretações desses mesmos princípios normativos: "a legitimidade dos processos do mercado tem de ser avaliada tanto por sua conformidade a certas normas legais, historicamente alcançadas, como pelo preenchimento de princípios específicos de mérito" (Honneth 2003c, 288). É, desse modo, a conformidade às normas legais e o preenchimento dos princípios de mérito que podem ser colocados em questão pelos movimentos sociais que lutam por uma redistribuição mais igualitária de recursos ou pela alteração na divisão social do trabalho.

Segundo Honneth, sempre que a economia capitalista viola as condições sociais para o desenvolvimento do autorrespeito e da autoestima, os sujeitos se sentem desrespeitados e podem se mobilizar para disputar o significado dos princípios de reconhecimento que a organizam. Eles podem lutar pela transformação do capitalismo mostrando que os direitos sociais existentes não dão conta de garantir as condições sociais para o autorrespeito e demandar, com isso, a ampliação do escopo desses direitos. Além disso, eles podem lançar mão do princípio da estima para mostrar que as contribuições realizadas por determinados grupos não estão sendo adequadamente valorizadas e reivindicar, dessa forma, maior 
valorização social. As lutas por redistribuição material seriam, então, lutas por reconhecimento, nas quais o que está em questão é a interpretação corrente dos princípios da estima social e do respeito. ${ }^{5}$

Ao lançar mão dessa estratégia, o objetivo de Honneth é mostrar que sua teoria do reconhecimento compreende as dinâmicas normativas da reprodução econômica e, diferentemente do modelo de teoria crítica desenvolvido por Habermas a partir de Teoria da Ação Comunicativa, permite uma crítica interna do capitalismo. Ao fazer isso, contudo, ele pressupõe que os mecanismos responsáveis pela distribuição de bens e recursos estão ancorados em uma interpretação desses princípios de reconhecimento, cuja alteração é tomada como o objetivo central das lutas por redistribuição. Segundo ele:

o que está sendo contestado [por essas lutas] é precisamente se, no que diz respeito à divisão atual do trabalho, os esquemas predominantes de valoração dos méritos e contribuições sociais são, de fato, justos (Honneth 2003b, 187).

Em outra passagem:

uma imagem suficientemente diferenciada desse tipo de luta por reconhecimento só é possível quando levamos em conta o fato de que mesmo a demarcação social de profissões - de fato, o formato da divisão social do trabalho como um todo - é o resultado da valoração cultural de capacidades específicas para o mérito (Honneth $2003 b, 182)$.

Nessas e em outras afirmações, Honneth defende que a economia é regida por princípios de reconhecimento e se desenvolve na direção de sua plena efetivação. Como afirma Simon Thompson a esse respeito, a teoria do reconhecimento tende a compreender todas as instituições sociais, dentre as quais a econômica, como resultado da cristalização de relações pré-institucionais de reconhecimento (Thompson 2005, 93).

Atentos a isso, diversos são os autores que acusam Honneth de compreender o capitalismo e seu desenvolvimento de forma inadequada. Dentre estes, foi Nancy Fraser quem o criticou com maior ênfase a esse respeito. Segundo ela:

as sociedades capitalistas contemporâneas estão permeadas por ideologias sobre o quanto várias atividades contribuem para o bem estar social. (...) essas ideologias têm efeitos reais. Mas elas dificilmente são os únicos fatores que afetam as variações salariais. Os fatores político-econômicos também são importantes, tais como a oferta e a demanda para diferentes tipos de trabalhos, a balança de poder entre trabalho e capital, a força das regulações sociais, incluindo o salário mínimo, a disponibilidade e o custo da melhora na tecnologia, a facilidade com que firmas podem mudar suas operações para lugares nos quais as bases salariais são menores, o custo do crédito e 
as taxas internacionais de câmbio (Fraser 2003, 215).

Tendo em vista os fatores político-econômicos que influenciam a divisão social do trabalho e a distribuição dos recursos materiais, Fraser afirma que uma teoria social crítica não pode deixar de tematizá-los e questioná-los. Por esse motivo, além de apontar para a importância dos mecanismos econômicos de integração, ela também ressalta - ao lado das lutas por reconhecimento - a importância das lutas por redistribuição (Fraser 2001). Lutas que visam, segundo ela, alterar ou regular os mecanismos econômicos que geram desigualdade material e não apenas modificar a interpretação corrente de princípios do reconhecimento.

Apesar de seu debate com Honneth ser referência nessa questão, Fraser não está sozinha nessa crítica. Para Rainer Forst, por exemplo, as injustiças materiais não estão sempre ligadas ao reconhecimento, nem têm como ser combatidas por meio de lutas que visam alterar a interpretação dos princípios do respeito e da estima. De acordo com ele, embora seja "verdade que o domínio econômico faz parte de um domínio cultural de reconhecimento", não é possível ignorar que "muitos fenômenos de injustiça nesse domínio parecem possuir outras causas e seguir uma lógica de mercado ou uma lógica 'sistêmica' que tem de ser identificada e criticada" (Forst 2008, 138). Também Christopher Zurn problematiza a tendência de Honneth de reduzir o capitalismo à ordem de reconhecimento da sociedade. Partindo de um artigo onde Honneth apresenta a democracia como uma forma de cooperação reflexiva (Honneth 2001a), Zurn procura mostrar que ele também compreende a economia como um âmbito de cooperação social no interior do qual os trabalhadores satisfazem reciprocamente suas necessidades. Para Zurn, ao fazer isso, Honneth desenvolve uma noção truncada de economia e propõe soluções práticas inadequadas à superação das injustiças materiais (Zurn 2005).

Apontando nessa mesma direção, até mesmo aqueles que defendem os potenciais críticos da teoria do reconhecimento tendem a concordar que não é possível explicar os mecanismos de distribuição material ou a divisão social do trabalho apenas com base nos princípios da estima e do respeito. Tanto Emmanuel Renault e Deranty, como Eleonora Piromalli e Marjan Ivković admitem que Honneth assume uma visão simplista da sociedade sempre que tenta explicar os mecanismos de integração que coordenam a ação econômica remetendo-se apenas aos princípios institucionalizados do reconhecimento. Segundo Deranty, para superar o antinormativismo de Habermas, Honneth teria compreendido o trabalho apenas do ponto de vista das relações intersubjetivas. Ao fazer isso, porém, ele não teria resolvido o problema, mas apenas substituído um reducionismo por outro (Deranty 2009, 49). Para 
Piromalli e Ivković, por sua vez, a tentativa de entender o capitalismo a partir de uma teoria do reconhecimento torna o modelo crítico de Honneth empiricamente inadequado (Ivković 2014, Piromalli 2012). Nesse mesmo sentido, Renault afirma que a teoria de Honneth perde sua plausibilidade nas passagens em que reduz a sociedade à sua ordem de reconhecimento (Renault 2004).

Assim, embora muitos ressaltem a importância da tentativa de Honneth de recolocar a economia em disputa, há um certo consenso de que a transformação do capitalismo e a superação das injustiças materiais não dependem apenas de lutas para alterar a interpretação social dos princípios da estima e do respeito. ${ }^{6} \mathrm{Na}$ medida em que não reconhece a especificidade dos mecanismos econômicos de integração, Honneth teria desenvolvido uma teoria social monista e excessivamente simplista.

Esse não parece ser, porém, o único problema decorrente da abordagem honnethiana. Para Fraser, ao sustentar que todas as esferas sociais estão ancoradas em princípios de reconhecimento e se reproduzem na direção de sua plena efetivação, além de não compreender os mecanismos econômicos de reprodução, Honneth também corre o risco de aproximar demais as instituições existentes dos princípios normativos do reconhecimento (Fraser 2003, 201-211). Isso porque, ao explicitar sua normatividade, Honneth daria a impressão de que todas são morais e se desenvolvem em direção à efetivação do excedente normativo dos princípios de reconhecimento. A economia é reconstruída como um âmbito de relações cooperativas, que se desenvolve em direção à democratização da estima; o direito é retratado como um domínio de relações entre iguais, que caminha em direção à institucionalização do respeito; a família, um dos campos mais importantes de subjugação feminina, é compreendida como o domínio do afeto, no interior do qual as pessoas são amadas e reconhecidas em suas carências. De acordo com Fraser, ao compreender a sociedade como uma teia de relações de reconhecimento, cujo desenvolvimento ocorreria por meio de lutas morais, Honneth pinta um quadro excessivamente "positivo" da realidade e chega, com isso, a um passo de justificá-la (Fraser 2003). David Owen e Bert van den Brink explicitam essa crítica ao afirmarem que Honneth:

foi muito criticado por tomar uma posição que parece ingênua ou mesmo afirmativa no que diz respeito às injustiças estruturais que estão inscritas no casamento burguês e em formas escondidas de sexismo, etnocentrismo e mesmo na exploração econômica inscrita nas instituições, nos padrões sociais de expectativa e na avaliação normativa característicos das democracias ocidentais (Owen e Brink 2007, 20). 
Renault também aponta nessa direção. Para ele, quando Honneth afirma que as três esferas socialmente diferenciadas produzem promessas universais e se desenvolvem no caminho de sua plena efetivação, sua teoria perde parte do potencial crítico. Afinal, com essa tese, ele parece tomar a estrutura e a dinâmica de desenvolvimento das sociedades modernas como racionais. Honneth teria recaído no mesmo erro que critica em Hegel: toma a sociedade como se ela já fosse racional e deixa de lado qualquer noção de negatividade ou irracionalidade (Renault 2011, 216-217). Reduzindo toda a realidade social às relações horizontais de reconhecimento, ele não conseguiria compreender o papel muitas vezes patológico exercido pela economia, bem como por valores e instituições nos processos de desenvolvimento social. O resultado, diz Renault, é uma teoria que não compreende as formas econômicas de exploração, nem os fenômenos de dominação simbólica.

Nesse mesmo sentido, Nicholas Smith afirma que Honneth se excedeu ao tentar corrigir o antinormativismo habermasiano. O objetivo de superar o déficit sociológico da teoria crítica teria levado Honneth a defender que a reprodução da sociedade está inteiramente atrelada à integração social e, portanto, à gramática moral do reconhecimento. Segundo Smith, "para exorcizar o espectro do homo economicus e erradicar a base antropológica do antinormativismo, Honneth acentua o normativo. Ao fazer isso, contudo, ele se torna claramente vulnerável a problemas como normativismo, culturalismo e idealismo" (Smith 2011, 339). Para Smith, ao reconstruir a interação social em termos morais e dizer que ela rege todos os processos sociais de reprodução, que jamais poderiam ser adequadamente compreendidos do ponto de vista de uma teoria dos sistemas, Honneth não deixaria espaço para a conceitualização de um tipo de ação ou mecanismo social que poderia ser responsável pela negação do reconhecimento. Denunciando o que chama de anti-antinormativismo, Smith também aponta então para a dificuldade de Honneth de explicar as origens sociais das injustiças, sejam elas materiais ou simbólicas.

Mobilizando passagens em que Honneth afirma que as relações de reconhecimento regem diretamente todos os processos sociais, esses autores acusam-no de ter aproximado demais o nível da reconstrução normativa do nível da teoria social. Erro que, além de tê-lo impedido de compreender o funcionamento da economia e de conceitualizar a negatividade do social, também o teria levado a defender uma visão excessivamente normativa da sociedade e de seus processos reais de desenvolvimento. Essa interpretação, contudo, está longe de constituir um consenso entre seus críticos e comentadores. Mesmo alguns dos autores citados acima procuram explorar ambiguidades textuais que permitem interpretações mais profícuas da teoria do reconhecimento, cujas consequências seriam menos devastadoras 
aos propósitos de Honneth (Renault 2004, 179-245).

\section{Monismo moral e dualismo teórico-social?}

Em um texto no qual procura rebater a acusação de que Honneth teria fechado os olhos a questões de desigualdade material, Majid Yar defende que seu monismo do reconhecimento não diz respeito à teoria social, mas sim aos efeitos subjetivos das diferentes formas de dominação, inclusive das econômicas (Yar 2001). Para ela, ao assumir uma posição monista, o objetivo de Honneth é apenas o de mostrar que, independentemente de suas origens específicas, as injustiças são sempre experiênciadas pelos indivíduos como violações do reconhecimento, ou seja, como violações de suas pretensões de identidade. Trata-se, assim, de explicitar que sempre que as condições sociais para a obtenção do reconhecimento são violadas por determinado mecanismo ou relação social, ele é tomado como injusto e pode ser alterado por meio de lutas sociais. Ao desenvolver uma teoria do reconhecimento, Honneth não estaria então tentando descrever empiricamente o funcionamento das sociedades modernas, mas reconstruindo sua gramática moral com base em uma fenomenologia do sofrimento social.

De acordo com Yar, quando afirma que todos os domínios sociais dependem de relações de reconhecimento, Honneth não quer dizer que eles se reproduzem diretamente por meio delas, mas sim que os sujeitos esperam ser reconhecidos de determinadas maneiras em seu interior. Trata-se apenas de mostrar que, como as pessoas confrontam todos os processos de reprodução social com expectativas de reconhecimento, eles estão submetidos aos seus princípios normativos e podem ser criticados em nome deles. Deranty também defende essa interpretação ao afirmar que, se "a teoria do reconhecimento, enquanto teoria social, não é suficiente para compreender a especificiadade da ação econômica, em oposição a outros tipos de ação social", ela "é extremamente útil, talvez insubstituível, para compreender a experiência da injustiça social, enquanto experiência social" (Deranty 2009, 413).

Ao adotar uma posição monista e afirmar que todas as lutas sociais podem ser compreendidas como lutas por reconhecimento, Honneth não estaria então ignorando os mecanismos econômicos, nem as lutas sociais por redistribuição que visam alterá-los. Pelo contrário, seu objetivo é acessar a gramática moral das sociedades modernas como um todo, por meio de uma reconstrução das expectativas morais de reconhecimento que desencadeiam os diferentes movimentos sociais, dentre os quais figuram tanto aqueles que questionam as 
hierarquias de valoração cultural como aqueles que questionam a atual forma de distribuição dos recursos materiais (Yar 2001). Nesse sentido, mesmo que as injustiças econômicas não sejam diretamente causadas por uma interpretação assimétrica dos princípios de reconhecimento, elas são patológicas na medida em que violam os padrões normativos de reconhecimento e geram experiências de desrespeito. ${ }^{7}$

É, tendo isso em vista, que Honneth sustenta que, embora os processos de reprodução social não sejam diretamente regidos pelos princípios do reconhecimento, todos eles possuem uma dimensão moral e estão sujeitos à crítica social (Honneth, 2003c, 285-286). Situado num nível mais abstrato, o monismo do reconhecimento possui um estatuto moral e não teóricosocial.

Até pelo menos Luta por Reconhecimento, entretanto, é difícil encontrar passagens que corroborem diretamente essa interpretação. ${ }^{8}$ Pelo contrário, preocupado com a superação dos déficits da teoria crítica, Honneth não só defende que o tecido da vida social é constituido por relações de reconhecimento, como também que o desenvolvimento da sociedade se dá por meio de conflitos morais. ${ }^{9} \mathrm{O}$ mesmo pode ser afirmado também a respeito de "Redistribuição como reconhecimento", sua primeira resposta às críticas de Fraser, onde o autor chega a defender que:

minhas reflexões até aqui me levam à conclusão de que uma concepção adequada da ordem social capitalista não requer apenas a inclusão de cada uma das três esferas sociais do reconhecimento, com cujos princípios normativos os sujeitos podem vincular expectativas legítimas de reconhecimento recíproco; pelo contrário, ela também necessita de uma consideração daqueles valores culturais que, por meio da atual interpretação do princípio do mérito, influenciam a constituição da esfera econômica e conferem a ela uma feição específica na forma da divisão do trabalho e da distribuição do status (Honneth 2003b, 185).

É, apenas em "O ponto do reconhecimento", sua segunda contribuição à Redistribuição ou Reconhecimento?, que o autor reconhece explicitamente a economia e suas formas de reprodução não estão diretamente ancoradas na ordem de reconhecimento da sociedade. Ao apontar para a existência de um tipo "sistêmico" de integração que não é diretamente coordenado pelos princípios do reconhecimento, ele rejeita que a esfera econômica seja moldada pela atual interpretação do princípio do mérito. Como diz ele, nesse texto, "alguns media generalizados, como o dinheiro ou o poder político, podem coordenar a interação social de forma relativamente inquestionada" (Honneth 2003c, 294).

De acordo com Honneth, contudo, essa questão não é tão importante, pois em nenhum momento ele teria ignorado a realidade social dos mecanismos econômicos de integração. Se 
não os abordou, afirma, é apenas porque seu objetivo nunca foi o de desenvolver uma teoria do capitalismo, mas sim o de mostrar que a inclusão das pessoas na sociedade ocorre por meio da expansão das relações de reconhecimento recíproco. Sua intenção, defende, sempre foi a de mostrar que "a integração social, em oposição à integração sistêmica, deve ser entendida como o resultado de processos de reconhecimento por meio dos quais os sujeitos são normativamente incorporados à sociedade" (Honneth 2003c, 286-287).

Yar estaria, portanto, com a razão. Ao reconstruir a gramática moral do reconhecimento, Honneth não teria tentado descrever o funcionamento da economia, mas sim a lógica moral dos processos sociais de integração, por meio dos quais os membros da sociedade aprendem a se afirmar intersubjetivamente. Como defende ele, "minha tentativa de reconstruir a ordem de reconhecimento das sociedades capitalistas modernas visava apenas revelar os princípios normativos que estruturam, em grande medida, os processos comunicativos de dentro" (Honneth 2003c, 287).

Independentemente de aceitarmos que essa foi sua intenção desde o início, o fato é que, em sua tréplica a Fraser, Honneth procura acabar com qualquer ambiguidade a esse respeito. Se, em textos anteriores, ele parecia confundir o nível da reconstrução normativa com o nível da descrição social, se tornando vulnerável à acusação de normativismo, agora ele diferencia esses níveis e defende que o monismo do reconhecimento possui um caráter moral e não teórico-social. Embora não especifique qual é exatamente a relação existente entre as formas sociais e sistêmicas de integração (Honneth 2003c, 285), Honneth diz claramente que a economia capitalista possui uma lógica específica de reprodução que não é diretamente regida pelos princípios do reconhecimento.

Para Renault, com esse passo, Honneth abre caminho para uma conceitualização mais adequada da economia e faz com que sua teoria do reconhecimento ganhe em plausibilidade. Ao atribuir certa autonomia ao mercado, além de compreendê-lo melhor, Honneth também poderia mostrar que os mecanismos econômicos possuem uma lógica de desenvolvimento que vai, muitas vezes, na contramão da dinâmica moral das relações de reconhecimento. De acordo com Renault, contudo, os ganhos propiciados com isso não veem sem antes gerar um certo prejuízo (Renault 2004). Isso porque, ao aceitar que a economia funciona de forma relativamente inquestionada, Honneth parece defender uma posição teórico-social dualista que, por diferenciar formas sistêmicas e sociais de integração, parece ir na contramão de sua intenção original, a saber, a de recolocar o capitalismo sob o alcance da crítica.

Ao apontarmos nessa direção, entretanto, só estamos levando em conta uma parte da 
história. Afinal, se Honneth afirma que o dinheiro e o poder dispõem de certa autonomia, ele o faz apenas para defender, logo em seguida, que "mesmo eles dependem de alguma crença em sua legitimidade, que pode enfraquecer ou desaparecer inteiramente a qualquer momento" (Honneth 2003c, 294). O alto grau de cooperação exigido para a reprodução da economia faz com que seu funcionamento não possa ser explicado sem a pressuposição dessa crença. Para Honneth, o dinheiro e o poder só são capazes de coordenar a interação porque os membros da sociedade os vêem como legítimos. Sempre que a crença em sua legitimidade for abalada, tais mecanismos de reprodução podem ser questionados e transformados.

Embora admita que a economia não se reproduz diretamente por meio de relações de reconhecimento, Honneth afirma em "O ponto do reconhecimento" que ela não está descolada das expectativas de reconhecimento sustentadas pelos sujeitos. O simples fato de que aqueles que são afetados pelas atuais transformações econômicas "experienciam a desregulação do trabalho como uma perda de direitos e pressionam por correções internas” já mostra, segundo ele, que mesmo "processos econômicos aparentemente 'anônimos' estão impregnados por regras normativas" (Honneth, 2003c, p. 292). Para o autor, portanto, ainda que não sejam suficientes para explicar integralmente suas dinâmicas internas de funcionamento, as expectativas normativas dos sujeitos não podem ser totalmente excluídas de uma análise do desenvolvimento do mercado de trabalho (Honneth 2003c, 287-291).

Ainda que essas passagens abram, novamente, um espaço para questionamentos sobre qual é o papel exercido pelas relações e expectativas de reconhecimento no interior dos processos materiais de reprodução ou mesmo sobre quais são, afinal, as pretensões descritivas da teoria do reconhecimento, o importante aqui é notar que, mesmo depois de admitir que o capitalismo se reproduz de modo quase inquestionado, Honneth não neutraliza a economia por completo. O reconhecimento da especificidade dos mecanismos econômicos de reprodução social não significa, para ele, que eles não têm uma dimensão normativa ou que as lutas por reconhecimento não possuem qualquer influência no interior do mercado. ${ }^{10}$ Ele não recairia, portanto, no déficit sociológico que critica em Habermas.

Além disso, é importante sublinhar que, ao recusar uma posição monista no âmbito da teoria social, Honneth apresenta uma possível explicação para a origem das violações do reconhecimento. Isso porque, ao explicitar que os processos econômicos não são diretamente regidos pelos princípios do reconhecimento, ele passa a ter como mostrar que os últimos podem ser socialmente negados pelos primeiros. ${ }^{11}$ Ao atentar para a especificidade dos mecanismos econômicos, Honneth apresenta então uma resposta àqueles que o acusam de ter ignorado as injustiças econômicas e os movimentos sociais que as combatem. 
Por outro lado, no entanto, os argumentos apresentados até aqui não parecem livrá-lo da crítica de que teria reduzido a interação social à sua dimensão moral. Por esse motivo, cabe também analisar em que medida Honneth não iguala a reconstrução normativa dos processos sociais de integração a uma descrição desses mesmos processos. Erro este que o tornaria vulnerável às criticas de normativismo, ainda que de modo mais restrito (já que limitado à dimensão social e não sistêmica de integração).

\title{
Monismo moral sem teoria social?
}

Como vimos acima, para se defender das acusações de que teria afirmado que o mercado capitalista é regido pela gramática moral do reconhecimento, Honneth sustenta que seu objetivo nunca foi o de dar conta da ação econômica ou o de desenvolver uma teoria do capitalismo contemporâneo. Ao defender que o mercado está submetido ao reconhecimento, seu objetivo teria sido somente o de mostrar que as instituições do mercado capitalista e do trabalho assalariado podem ser criticadas em nome dos princípios de reconhecimento (Renault 2004, 212).

Embora, em alguns momentos, essa ressalva pareça se restringir às esferas sociais que não dependem diretamente da interação social para se reproduzirem, em outros, Honneth amplia seu escopo e defende que sua teoria não possui pretensões descritivas. É isso que podemos depreender, por exemplo, de um trecho no qual ele afirma que sua teoria não visa descrever o funcionamento das sociedades contemporâneas:

\begin{abstract}
não vinculo quaisquer objetivos explicativos à tentativa de reconstruir a ordem de reconhecimento das sociedades capitalistas modernas; não se trata de estabelecer um quadro categorial básico, com cujo auxílio seria possível explicar adequadamente os processos de desenvolvimento no interior de tais sociedades. Meu objetivo era consideravelmente mais modesto, antes de tudo, queria apenas revelar as "coerções" morais que subjazem, em diferentes níveis, à interação social nessa forma de sociedade (Honneth 2003c, 286).
\end{abstract}

Honneth teria se limitado a afirmar que os processos de reprodução simbólica, tal como os de reprodução material, são normativamente regulados. Não se trata, assim, de propor uma reedição mitigada e modificada do dualismo entre sistema e mundo da vida. Afinal, mesmo aceitando uma distinção entre os diferentes tipos de integração, Honneth não busca descrevê-los, mas apenas explicitar que eles estão submetidos a coerções normativas. Seu objetivo, nesse sentido, é apenas o de mostrar que os princípios do reconhecimento 
exercem uma pressão normativa sobre a realidade, pois se encontram socialmente institucionalizados, e não que eles regem diretamente os processos de reprodução social.

Longe de resolver o problema, entretanto, essa afirmação parece apenas recolocá-lo de outro modo. Afinal, agora se torna necessário analisar o que significa defender que os princípios do reconhecimento se encontram socialmente institucionalizados e exercem uma pressão normativa sobre a realidade, mesmo depois de admitir que não eles não possuem um estatuto descritivo.

\section{Reconstrução normativa e teoria social}

Como mostramos acima, há vários momentos em que Honneth atribui pretensões descritivas ao monismo do reconhecimento. ${ }^{12}$ Apesar disso, é possível encontrar em seu trabalho diversas outras passagens que permitem uma interpretação distinta. Nestas, Honneth ressalta que, ao afirmar que nenhuma esfera da sociedade escapa à dinâmica moral das formas sociais de integração, ele não quer dizer que os padrões normativos do reconhecimento regem todas elas, nem que eles se encontram plenamente efetivados nas sociedades capitalistas contemporâneas. Pelo contrário, ele reconhece que os padrões normativos do reconhecimento são constantemente violados e não estão plenamente efetivados.

Isso, contudo, também não significa admitir, de acordo com ele, que esses mesmos padrões não se encontram socialmente institucionalizados. Afinal, a realidade social dos padrões normativos do reconhecimento pode ser demonstrada a partir de uma reconstrução das expectativas que os sujeitos sustentam frente aos seus parceiros de interação. Como afirma ele, nessa direção:

\footnotetext{
aquilo que podemos compreender como uma busca por reconhecimento parece inicialmente em uma forma negativa, a saber, como a experiência de humilhação ou desrespeito. Somente depois de realizar uma análise mais detida e revelar os pontos normativos de referência que permanecem frequentemente inarticulados na realidade cotidiana, é que se torna aparente que essas experiências negativas estão implicitamente baseadas em uma demanda por uma forma, previamente negada, de reconhecimento (Honneth 2007a, xii-xiii).
}

É, assim, com base em uma fenomenologia do sentimento de desrespeito, que Honneth explicita a realidade social dos princípios simétricos do amor, do respeito e da solidariedade.

Ao defender que os princípios do reconhecimento se encontram socialmente institucionalizados, Honneth não está defendendo, portanto, que é possível descrever a realidade social com base neles, mas apenas mostrando que eles se já encontram 
institucionalizados nas expectativas morais dos sujeitos e podem ser tomados como ponto de partida de uma crítica imanente da sociedade. ${ }^{13}$ Afinal, embora não sejam responsáveis por reger diretamente os processos sociais de reprodução, esses princípios exercem sobre eles, na forma de conflitos sociais, uma pressão normativa que possibilita a identificação de uma tendência à emancipação na realidade.

Ao reconstruir os princípios de reconhecimento, Honneth está apontando para os potenciais de desenvolvimento moral contidos na sociedade, que o permitem defender que as relações recíprocas de reconhecimento tendem a ser ampliadas. Longe de corresponder a uma reafirmação do real, a reconstrução normativa empreendida por ele visa então explicitar seu potencial emancipatório. Como afirma Deranty, a esse respeito, "as reações afetivas negativas apontam para a transcendência do reconhecimento pleno no interior da imanência de uma ordem social baseada na falta ou na negação do reconhecimento" (Deranty 2009, 315).

Essa estratégia negativa de reconstrução é, além disso, central para compreendermos como Honneth procura realizar uma crítica imanente da sociedade com base em um conceito de eticidade. Isso porque, é com base em uma antecipação do resultado das lutas por reconhecimento que Honneth chega, ao final de Luta por reconhecimento, ao conceito formal de eticidade (Honneth 2003a, 269-280). A ordem de reconhecimento reconstruída por ele não corresponde, assim, a uma descrição da realidade social, mas à explicitação do excedente normativo contido nos padrões de reconhecimento implícitos nas expectativas morais dos sujeitos modernos e nos conflitos sociais. Trata-se da explicitação de como seria uma sociedade na qual o excedente normativo dos princípios do reconhecimento estivesse plenamente efetivado, uma sociedade na qual as condições sociais à autorrealização pessoal estivessem presentes. Longe de corresponder a uma descrição ou a uma justificação das sociedades capitalistas contemporâneas, o conceito de eticidade formal corresponde ao critério imanente que permite a Honneth criticar a falta ou a violação do reconhecimento.

Ao enfatizamos a estratégia reconstrutiva mobilizada por Honneth, vemos então que ele não visa defender que a sociedade já é plenamente racional, nem elaborar uma teoria excessivamente normativa dos processos reais de desenvolvimento social. O que ele busca fazer, pelo contrário, é reconstruir os elementos normativos contidos nas experiências de desrespeito que permitem tanto a crítica imanente da sociedade quanto a superação prática dos bloqueios sociais à emancipação (Honneth 2007c).

É, nesse sentido, que podemos compreender as respostas dadas por ele a ressalvas feitas por diferentes teóricas feministas como, por exemplo, Iris Young e Nancy Fraser (Young 
2007). De acordo com ele, ainda que Young tenha razão em mostrar que as famílias continuam hoje muito longe de corresponderem a um domínio em que a interação seja regulada por uma forma simétrica de cuidado e afeto - que na maior parte das vezes é realizado por mulheres e cobrado apenas delas -, é somente com base nesse padrão recíproco de reconhecimento que tais assimetrias podem ser criticadas (Honneth 2007d, 356-362). Um argumento semelhante é mobilizado por ele também em sua resposta a Fraser. Enquanto ela defende que a esfera do trabalho não corresponde a um domínio regulado por princípios simétricos de reconhecimento, mas sim a um domínio assimétrico e desigual, ele afirma que é apenas porque os mecanismos econômicos de integração são confrontados pelos concernidos com expectativas de reconhecimento, que eles podem ser questionados e alterados por eles. Honneth não teria ignorado, então, a complexidade dos mecanismos sociais de reprodução nem a existência de diferentes causas de patologias sociais.

Desse modo, embora não sejam poucos aqueles que questionam Honneth por ter aproximado demais a descrição da realidade da reconstrução de sua dimensão normativa, os princípios de reconhecimento não parecem cumprir, para ele, uma função de descrição e, portanto, de legitimação da sociedade. Na medida em que parte de uma fenomenologia da experiência do desrespeito, Honneth teria como identificar a transcendência no interior da imanência sem assumir uma visão normativizada da última. A retomada da estratégia negativa de reconstrução mobilizada por ele parece permitir, portanto, não apenas uma clarificação de sua posição sobre o estatuto do monismo do reconhecimento, como também uma resposta às críticas de que sua teoria do reconhecimento estaria ancorada diretamente sobre uma compreensão normativa da sociedade e de seus mecanismos de reprodução (Honneth 2003c).

Apesar de suas virtudes e da importância que exerce nos primeiros textos de Honneth, vale ressaltar aqui que essa estratégia não é isenta de problemas, ${ }^{14}$ nem parece ter sido mantida pelo autor em seus textos mais recentes. ${ }^{15}$ Afinal, a partir de Sofrimento de indeterminação Honneth abandona a experiência de desrespeito como ponto de partida de sua teoria e começa a desenvolver uma nova concepção de reconstrução normativa por meio da qual procura explicitar as estruturas normativas das sociedades modernas (Honneth 2007c, Honneth 2007b, Honneth 2011). Ao fazer isso, porém, ele não rejeita a tese de que o monismo do reconhecimento possui um estatuto moral e não teórico-social. O que ele faz, antes, é desenvolver um novo conceito de reconstrução normativa que o permite explicitar, de outro modo, a gramática moral das sociedades modernas sem defender, com isso, que ela já se encontra plenamente efetivada nelas. 


\section{Notas:}

${ }^{1}$ Agradeço à FAPESP pelo financiamento da pesquisa que deu origem a esse artigo. Agradeço também a todos aqueles que participaram das discussões de diferentes versões desse texto, principalmente a Ricardo Terra.

2 Professora na Universidade Federal do ABC (UFABC), São Bernardo do Campo, SP, Brasil. E-mail: nathalie.bressiani@ufabc.edu.br

3 De acordo com ele, as formas rudimentares de afeto e amor presentes nas sociedades pré-modernas fizeram, pouco a pouco, com que as pessoas fossem se dando conta de suas necessidades físicas e emocionais. No decorrer desse processo, teria se tornado claro o quão importante o cuidado dos pais é para o desenvolvimento da personalidade da criança e para o estabelecimento de sua autoconfiança. Nesse mesmo período, também as relações afetivas, até então submetidas a pressões econômicas e sociais, teriam se diferenciado: casamentos arranjados deram gradativamente lugar a relações baseadas no amor existente entre os parceiros, ao mesmo tempo em que amizades deixaram de ser pautadas pelo interesse. Como resultado, afirma Honneth, ocorreu a institucionalização dos princípios do afeto e do cuidado que, na modernidade, regulariam as relações de reconhecimento entre familiares e amigos. Além do surgimento dessa forma de integração, a modernidade também se caracteriza pela diferenciação das relações de respeito e de estima. Segundo Honneth, enquanto em sociedades pré-modernas os direitos e os deveres de cada indivíduo, bem como a estima desfrutada por ele dependiam diretamente da honra atribuída ao grupo social do qual fazia parte, na modernidade prevalece a ideia de que todos são livres e iguais. O desenvolvimento do capitalismo burguês teria feito com que a distinção de status e a ordem hierárquica de valores, que regulavam a atribuição de honra a cada pessoa, desmoronassem. Com isso, todos passaram a ser vistos como iguais e dignos de respeito, independentemente de suas origens ou posses. Da mesma forma, a estima social desfrutada pelo indivíduo, que dependia até então do status que lhe cabia em função de seu pertencimento a determinado grupo, passa a depender das contribuições individuais que faz à reprodução material da sociedade (Honneth 2003b, 162-170).

${ }^{4}$ Levando em conta a mudança na posição de Honneth depois de Luta por Reconhecimento, apresento a terceira esfera tal como ela é descrita em Redistribuição ou Reconhecimento?, a saber, como ligada à divisão social do trabalho (Honneth 2003b).

${ }^{5}$ Como afirma Honneth: "há dois modos pelos quais os sujeitos podem reivindicar o reconhecimento de sua situação de vida particular ou personalidade para lutar por maior estima social e, portanto, mais recursos. Por um lado, é possível demandar, até um ponto politicamente negociado, pela aplicação dos direitos sociais que garantem a todo membro da sociedade um mínimo de bens sociais independentemente de seus méritos (...). Por outro lado, no entanto, na realidade social do capitalismo, também há a possibilidade de mostrar os méritos de alguém como algo "diferente", uma vez que eles não recebem consideração suficiente ou estima social sob a atual estrutura hegemônica de valor" (Honneth 2003b, 181-182).

${ }^{6}$ Vale ressaltar aqui que: dizer que a transformação do capitalismo e a superação das injustiças materiais não dependem apenas de lutas para alterar a interpretação social dos princípios da estima e do respeito não é o mesmo que defender que o capitalismo e seus mecanismos de reprodução não podem ser alterados (de fora) em nome desses mesmos princípios.

${ }^{7} \mathrm{Na}$ mesma medida em que podem garantir o reconhecimento, as relações econômicas podem também violá-lo e gerar experiências de sofrimento. É, nesse sentido, que Honneth defende que todos os fenômenos sociais possuem uma dimensão moral e estão sujeitos à crítica social (Honneth, 2003c, 285-286).

${ }^{8}$ Logo depois de afirmar que Honneth não procura reduzir a sociedade à sua ordem de reconhecimento, Deranty admite que essa é uma posição de difícil sustentação pois "há muitas passagens onde a rejeição dos argumentos funcionalistas e o desejo de salvar a possibilidade da práxis são tão fortes que a linha que Honneth parece querer defender se torna perigosamente próxima da perspectiva reducionista [na teoria social]" (Deranty 2009, 347).

${ }^{9}$ Isso, segundo ele, mesmo nos casos em que os próprios atores não se dão conta de sua motivação moral e a interpretam, erroneamente, na chave do interesse pessoal (Honneth 2003a, 257-258). 
${ }^{10} \mathrm{Em}$ "O ponto do reconhecimento", Honneth parece assumir uma posição semelhante à de Fraser, segundo a qual, apesar de depender de normas e valores sociais, a economia se caracteriza também por seguir determinados princípios funcionais de reprodução. Ao mesmo tempo, ele não adota a posição dela no que diz respeito à conceitualização da gramática normativa dos movimentos sociais, que são compreendidos por ele em uma única chave: a da gramática moral do reconhecimento. Embora permaneça fiel a essa segunda tese, textos mais recentes de Honneth podem ser interpretados como uma tentativa de rever a primeira (Cf. Honneth 2011, 317 469).

11 Segundo Honneth: “as expectativas que os indivíduos podem articular são continuamente minadas por processos de mercado supostamente anônimos e livres de normas". Isso, contudo, só é possível "porque suas pretensões de reconhecimento já estão institucionalizadas, de alguma forma, nas regulações legais ou nos esquemas de pagamentos" (Honneth 2003c, 290).

12 Embora defenda que o reconhecimento abarca a gramática moral da sociedade como um todo, Honneth explicita que esta não se reduz a um único princípio de reconhecimento, mas abarca os três diferentes princípios e possui, portanto, um caráter pluralista (Honneth 2004).

13 Como afirma Honneth, "formas de reconhecimento recíproco estão institucionalizadas desde sempre na realidade social, cujos déficits e assimetrias são, de fato, aquilo que pode desencadear um tipo de 'luta por reconhecimento"" (Honneth 2003b, 161).

${ }^{14}$ Se aceitamos, como o faz Honneth, que a realidade social está perpassada por assimetrias de poder e relações de dominação, não é possível ignorar a influência exercida por elas no interior dos processos sociais de construção da identidade e de formação das expectativas dos sujeitos. Assim, ainda que a explicitação de seu conceito de reconstrução fornece uma resposta à acusação de que Honneth teria confundido o nível da reconstrução normativa com aquele da teoria social, a resolução dessa questão parece exigir mais uma análise. Caberia ainda verificar, nesse sentido, se, ao atribuir um estatuto moral ao sentimento de desrespeito, a teoria do reconhecimento não acaba pressupondo uma noção normativizada dos processos de socialização e individuação e, portanto, da própria sociedade (McNay 2008; Patherbridge 2013).

${ }^{15} \mathrm{O}$ motivo, fornecido por ele posteriormente, decorre do fato de que "a fundamentação dos padrões da crítica nas experiências de desrespeito está acompanhada do risco de aceitar todas as expectativas como justificadas" (Honneth e Boltanski 2008, 97). 


\section{Referências Bibliográficas:}

DERANTY, Jean-Philippe. Beyond Communication. A critical study of Axel Honeth's Social Philosophy. Leiden; Boston: Brill, 2009.

FORST, Rainer. "First things first: redistribution, recognition and justification." In: Nancy Fraser; Kevin Olson. Adding Insult to Injury: Nancy Fraser Debates Her Critics. New York: Verso, 2008, pp. 310-326.

FRASER, Nancy. "Da Redistribuição ao Reconhecimento? Dilemas da Justiça na Era PósSocialista." In: Jessé Souza. Democracia Hoje. Novos Desafios para a Teoria Democrática Contemporânea. Brasília: UNB, 2001, pp. 245-282.

. "Distorted Beyond All Recognition: A Rejoinder to Axel Honneth." In: Nancy Fraser; Axel Honneth. Redistribution or Recognition? A political-philosophical exchange. New York: Verso, 2003, pp. 198-236.

HABERMAS, Jürgen. Theorie des kommunikativen Handelns. Zur Kritik der funktionalistischen Vernunft. Frankfurt am Main: Suhrkamp, 1995.

HONNETH, Axel. "Arbeit und instrumentales Handeln. Kategoriale Probleme einer Kritischen Gesellschatstheorie." In: Axel Honneth; Urs Jaeggi. Arbeit, Handlung, Normativität. Theorien des Historischen Materialismus 2. Frankfurt am Main: Suhrkamp, 1980, pp. 185-233.

. Kritik der Macht. Reflexionsstufe einer kritischen Gesellschaftstheorie. Frankfurt am Main: Suhrkamp, 1989.

. "Introduction." In: The fragmented world of the social. Essays in social and political pgilosophy. New York: State University of New York Press, 1995, pp. xi-xxv.

. "Die soziale Dynamik von Missachtung. Zum Ortbestimmung einer kritischen Gesellschaftstheorie." In: Das Andere der Gerechtigkeit. Aufsätze zur praktischen Philosophie. Frankfurt am Main: Suhrkamp, 2000, pp. 88-109.

. "Democracia como cooperação reflexiva: John Dewey e a teoria da democracia hoje.” In: Jessé Souza. Democracia Hoje. Brasília: Editora UnB, 2001a, pp. 63-92.

. Recognition or redistribution? Changing perspectives on the moral order of society. Theory, Culture and Society, v. 18, n. 2-3, pp. 43-55, $2001 \mathrm{~b}$.

. Luta por reconhecimento. A gramática moral dos conflitos sociais. São Paulo:

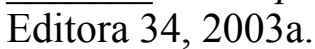

. "Umverteilung als Anerkennung. Eine Erwiderung auf Nancy Fraser." In: Nancy Fraser; Axel Honneth. Umverteilung oder Anerkennung? Eine politisch-philosophische Kontroverse. Frankfurt am Main: Suhrkamp, 2003b, pp. 129-224. 
. "Die Pointe der Anerkennung. Eine Entgegnung auf die Entgegnung." In: Nancy Fraser; Axel Honneth. Umverteilung oder Anerkennung? Eine politisch-philosophische Kontroverse. Frankfurt am Main: Suhrkamp, 2003c, pp. 271-305.

. Recognition and Justice. Outline of a plural theory of justice. Acta Sociologica, v. 47, n. 4, pp. 351-364, 2004.

. "Preface." In: Disrespect. The normative foundations of critical theory. Cambridge: Polity Press, 2007a, pp. xii-xiii.

. Sofrimento de Indeterminação. São Paulo: Esfera Pública, 2007b.

."Eine soziale Pathologie der Vernunft. Zur intellektuellen Erbschatf der Kritischen Theorie." In: Pathologien der Vernunft. Geschichte und Gegenwart der Kritische Theorie. Frankfurt am Main: Suhrkamp, 2007c, pp. 28-56.

. "Rejoinder." In: Bert van den Brink; David Owen Recognition and Power. Axel Honneth and the Tradition of Critical Theory. Cambridge: Cambridge University Press, 2007d, pp. 348-370.

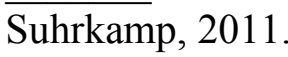

. Das Recht der Freiheit. Grundriss einer demokratischen Sittlichkeit. Berlin:

HONNETH, Axel; BOLTANSKI, Luc. "Soziologie der Kritik oder Kritische Theorie? Ein Gespräch mit Robin Celikates." In: Was ist Kritik?, por Rahel Jaeggi e Tilo Wesche. Frankfurt am Main: Suhrkamp, 2008.

IVKOVIĆ, Marjan. Axel Honneth's theory of the struggle for recognition: Towards a postmetaphysical critique of domination. University of Cambridge: PhD Thesis, 2014.

MCNAY, Lois. Against recognition. Cambridge: Polity Press, 2008.

OWEN, David; BRINK, Bert van den. "Introduction." In: David Owen; Bert van den Brink. Recognition and Power. Axel Honneth and the Tradition of Critical Social Theory. Cambridge: Cambridge University Press, 2007, pp. 1-30.

PATHERBRIDGE, Danielle. The critical theory of Axel Honneth. Plymouth: Lexington Books, 2013.

PIROMALLI, Eleonora. Axel Honneth. Giustizia Sociale come Riconoscimento. Milano: Mimesis, 2012.

RENAULT, Emmanuel. L'Expérience de l'Injustice. Paris: La Découverte, 2004.

. "The Theory of Recognition and Critique of Institutions." In: Danielle Patherbridge. Axel Honneth: Critical Essays. With a Reply by Axel Honneth. Leiden: Brill, 2011, pp. 207232. 
SMITH, Nicholas. "Recognition, Culture and Economy: Honneth's Debate with Fraser." In: Danielle Patherbridge. Axel Honneth: Critical Essays. With a Reply by Axel Honneth. Boston: Brill, 2011, pp. 321-344.

THOMPSON, Simon. Is redistribution a form of recognition? Comments on the FraserHonneth debate. Critical Review of international social and political philosophy, v. 8, n. 1, pp. 85-102, 2005.

YAR, Majid. Beyond Nancy Fraser's Perspectival Dualism. Economy and Society, v. 30, n. 3, pp. 288-303, 2001.

YOUNG, Iris Marion. "Recognition of Love's Labor: Considering Axel Honneth's Feminism." In: Bert van den Brink; David Owen Recognition and Power. Axel Honneth and the Tradition of Critical Social Theory. Cambridge: Cambridge University Press, 2007, pp. 189-212.

ZURN, Christopher. Recognition, Redistribution, and Democracy: Dillemas of Honneth's Critical Social Theory. European Jornal of Philosophy, v. 13, n. 1, pp. 89-126, 2005. 